\title{
Experimental Analysis of the Influence of Hydrostatic Stress on the Behaviour of an Adhesive Using a Pressure Vessel
}

\author{
J. Y. Cognard ${ }^{a},{ }^{*}$, R. Créac'hcadec ${ }^{a}$, L. F. M. da Silva ${ }^{b}$, F. G. Teixeira ${ }^{b, c}$, P. Davies ${ }^{d} \&$ M. Peleau ${ }^{d}$
}

\author{
a Laboratoire Brestois de Mécanique et des Systèmes, ENSTA Bretagne, Brest, France \\ ${ }^{b}$ Departamento de Engenharia Mecânica, Faculdade de Engenharia da Universidade do Porto, Porto, Portugal \\ c Departamento de Design e Expressão Gráfica, Universidade Federal do Rio, Grande do Sul, Porto Alegre, \\ Brasil \\ d Service Matériaux et Structures, IFREMER, Plouzané, France \\ *: Corresponding author : Jean-Yves Cognard : Tel : +33298348816; Fax : +33298348730 \\ email address : jean-yves.cognard@ensta-bretagne.fr
}

\begin{abstract}
:
The modelling of the non-linear behaviour of ductile adhesives requires a large experimental database in order to represent accurately the strains which are strongly dependent on the tensile-shear loading combination. Various pressure-dependent constitutive models can be found in the literature, but only a few experimental results are available, for instance, to represent accurately the initial yield surface taking into account the two stress invariants, hydrostatic stress, and von Mises equivalent stress. This paper presents the possibility of combining the use of tests on bulk specimens and tests on bonded assemblies, which strongly limit the influence of the edge effects, with a pressure vessel especially designed to study the influence of hydrostatic stress. The latter allows pressures up to $100 \mathrm{MPa}$ to be applied during mechanical testing. For a given strain rate of the adhesive, experimental results using various stress paths are presented in order to analyse the influence of the hydrostatic stress on the mechanical behaviour of an adhesive. The analysis of the results focuses herein on the modelling of the initial yield surface, but such results are also useful for the development of the flow rules in the case of 3D pressure-dependent models.
\end{abstract}

Keywords : Adhesive testing ; Finite element analysis ; Hydrostatic stress ; Modelling ; Non-linear behaviour ; Yield surface

\section{Introduction}

Adhesive bonding is nowadays a well established technique in different engineering fields [1-2]. Simple design rules exist for designing simple joints such as single lap joints which just rely on the adhesive elastic constants [3] or yielding stress [4]. However, for a more precise joint strength prediction, more information is needed about the adhesive constitutive behaviour. There are several types of tests available to generate test data for constitutive modelling. The tensile stress-strain curve on bulk specimens is generally the most common test used. This is sufficient if the yield behaviour of the adhesive is assumed to be of the von Mises type. However, it is known that adhesive yielding is better described by more complex yielding criteria [5-7] for which an additional test under a different loading condition is required. Shear tests are usually preferred because the compressive test is more difficult to perform. There are many test methods for the determination of failure strength data. Basically, they can be divided into two main categories: tests on bulk specimens and tests in a joint or in-situ. Tests in the bulk form are easy to perform and follow the standards for plastic materials. Tests 
in-situ more closely represent reality, but there are some difficulties associated with accurately measuring the very small adhesive displacements of thin adhesive layers. Moreover, the adhesive stress distribution is not perfectly uniform and the failure mode may not be the same as that found in real joints. Another important point is that the adhesive strength measured in a joint depends on the surface preparation. This is not only critical for the short-term strength but even more so for the long-term strength, especially if aggressive environments are present. There has been intense debate about the most appropriate method and whether the two methods (bulk and in-situ) can be related. Some argue that the properties in the bulk form may not be the same as in a joint because the cure in the bulk form and the cure in a joint (thin film) may not be identical. In effect, the adherends remove the heat produced by the exothermic reaction associated with cure and prevent overheating. However, many studies have shown that the relation is reasonable taking into account all the differences associated to each method [8-10]. Adhesive properties in tension, compression and shear are well correlated provided a model that takes into account the hydrostatic stress component is used. However, the prediction of the shear strain to failure does not compare well with the experimental value. The shear strain to failure is the most difficult parameter to obtain both in terms of accuracy and precision. It is highly dependent on the type of loading and quality of the specimen. The adhesive has a different behaviour when loaded in shear and in tension in the presence of defects such as voids. In tension, once a crack is triggered next to a void, the specimen fails due to the high stress concentration. In shear, even if a crack is triggered, the remaining area is capable of further deformation, especially if the adhesive is ductile. For example, in bulk tension, a small void will cause a premature failure whereas in the thick adherend shear test (TAST) for example, the presence of a void is not as critical. There have been recent advances in this area where the same type of specimen is used for all loadings giving very good results up to the failure strain [11-12]. The work presented here is a step further in the determination of a test that can provide reliable data for the adhesive constitutive modelling, taking into account the effect of hydrostatic stress. Two types of joints with reduced edge effects were studied: modified TAST and modified Arcan. These specimens were loaded in a jig that enables to apply mixed tension and shear loadings. An hydrostatic pressure was also applied through a pressure vessel filled with water in order to provide additional information regarding this important variable. Bulk specimens were also tested in tension and compression with hydrostatic pressure to relate bulk and in-situ properties.

\section{Presentation and properties of experimental tests}

In this section, the pressure vessel and the different tests used in the present study to analyse the influence of hydrostatic stress on the mechanical behaviour of an adhesive are described.

\subsection{Materials}

In the present study, the adhesive is the epoxy resin Huntsman ${ }^{\mathrm{TM}}$, Basel, Switzerland, Araldite ${ }^{\circledR} 420$ $\mathrm{A} / \mathrm{B}$, cured at $50^{\circ} \mathrm{C}$ for 4 hours after $12 \mathrm{~h}$ at $20^{\circ} \mathrm{C}$. Bonded assemblies were studied using aluminium substrates with a simple surface preparation (abrasion with 120 grade paper and acetone degreasing). For the bonded assemblies, the adhesive thickness was $0.2 \mathrm{~mm}$. As adhesives often show large viscous effects, in order to facilitate the comparison between the different experimental results, a constant strain rate in the adhesive was applied (of about 0.12 minute $^{-1}$ ).

\subsection{The experimental hydrostatic pressure device (CHEM pressure vessel)}

The CHEM (Caisson Hyperbare d'Essais Mécaniques) system [13] was designed at the IFREMER Brest Centre in order to study the influence of hydrostatic stress on the mechanical behaviour of materials. This pressure vessel allows pressures up to $100 \mathrm{MPa}$ (1000 bars) to be applied during mechanical testing. Thus, this vessel is particularly well-suited to analyse the behaviour of bonded 
assemblies [12] and the details of this vessel have been presented previously [14-15]. Figure 1(a) shows the CHEM pressure vessel mounted on a standard tensile testing machine. View-glasses can be used to see inside the pressure vessel up to a pressure of $60 \mathrm{MPa}$ which allow a non-contact measurement system by image correlation (Fig. 1(a)). It is important to note that measuring displacements in the CHEM pressure vessel through the view-glass with a digital camera is a difficult task, and requires great care with calibration and lighting. Above this pressure of $60 \mathrm{MPa}$, metallic closures have to be used instead of the view-glasses (Fig. 1(b)). After positioning the specimen in the tensile testing machine, the vessel is closed. During the closure of the vessel (descent of the upper part, Fig. 1(b)), some small movements of the upper part of the vessel can occur. Therefore, special fixing systems compatible with those movements were used in order to limit the preloading of the specimens. The screw-nut system presented in Fig. 1(b) was used to complete the vessel closure. The vessel was then filled with tap water and the required pressure was applied using a special pump. While the pressure increased, a specific two-chamber equilibrium system ensured no other preloading of the specimen. Thus, during this phase, the only loading of the specimen was due to the hydrostatic pressure. Then, a mechanical test, imposed by the tensile testing machine, can be performed at a given pressure in the vessel. The result is the superposition of two loadings: a hydrostatic pressure and a mechanical loading. All the tests presented below were performed by controlling the displacement of the crosshead of the tensile testing machine in order to have a strain rate of about 0.12 minute $^{-1}$.

A pressure of $0.5 \mathrm{MPa}$ (noted as 0 in the following) corresponds to a very low hydrostatic pressure loading of a specimen simply immersed in water. Tests were performed for hydrostatic pressures of: 0 , 30, 60 and $90 \mathrm{MPa}$.

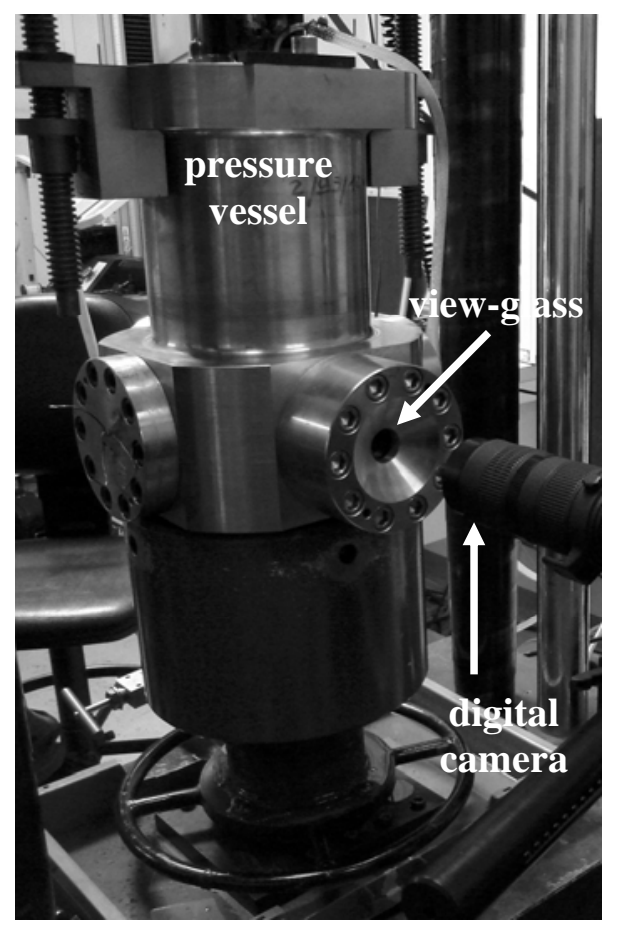

(a)

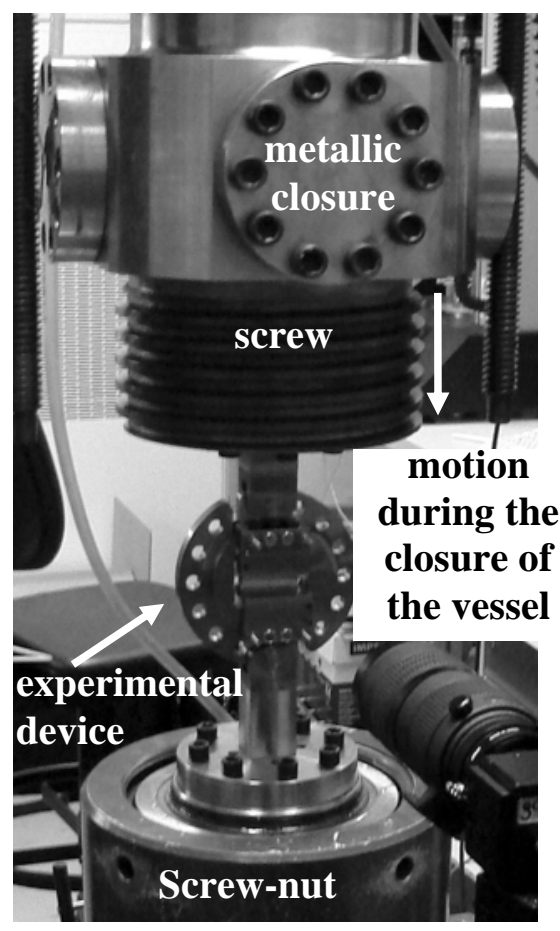

(b)

FIGURE 1 CHEM system description. (a) CHEM system with the use of a digital camera and (b) closing system (screw-nut) of the pressure vessel and positioning of the experimental device inside the pressure vessel.

\subsection{Tensile and compression tests on bulk specimens}

Bulk adhesive specimens were tested in the pressure vessel under traction and compression loadings (Fig. 2). The technique described in the French standard NF T 76-142 for producing plate specimens 
without porosity was used [10]. The specimens for tensile tests were machined from the plates to a dogbone geometry with a useful rectangular section of $10 \mathrm{~mm}$ x $4 \mathrm{~mm}$ and a useful length of $40 \mathrm{~mm}$. The system designed for the modified thick adherend shear test (TAST) was used to load the specimen [16]. The bulk specimen was fixed on two supports using clamping systems with bolts. In order to prevent parasitic loadings, connections allowing rotations were used (Fig. 2(a)): a universal joint ensures the radial positioning of the support in the vessel and the axial load is transmitted by a pin in order to control the geometrical constraints. For these tests, the crosshead displacement rate of the tensile testing machine was $5 \mathrm{~mm} /$ minute.

For compression tests, cylindrical specimens were used (diameter of $12.75 \mathrm{~mm}$ and length of 25.4 $\mathrm{mm}$ ). Specimens were machined from plate specimens. A specific device was used in order to ensure a precise compression loading (Fig. 2(b)). For these tests, a displacement rate of the crosshead of the tensile testing machine of $3 \mathrm{~mm} /$ minute was used.

Each test on a bulk specimen requires nearly an hour, taking into account the preparation phases, the closure of the vessel, increasing the pressure, the mechanical test and the opening of the vessel.

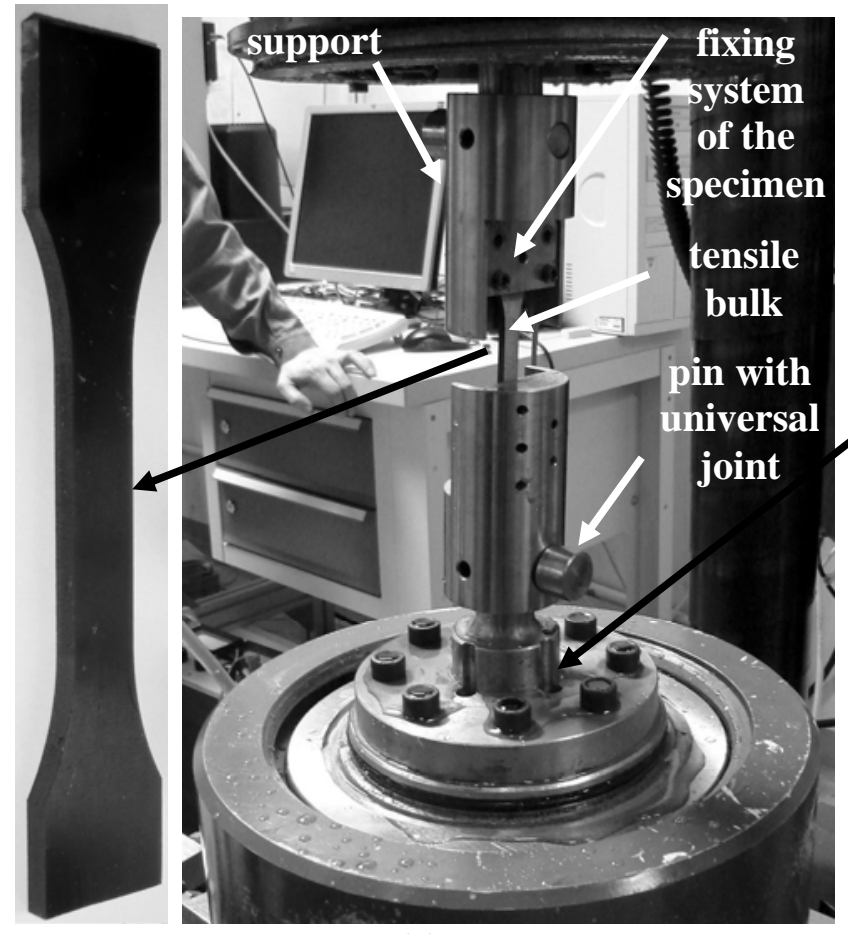

(a)

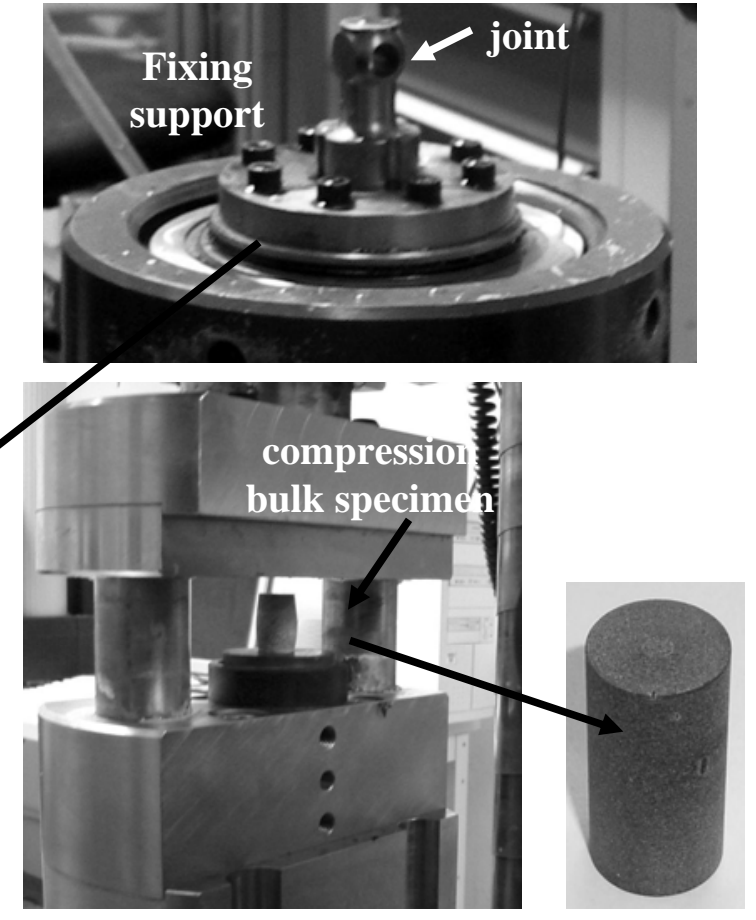

(b)

FIGURE 2 Bulk tests in the pressure vessel. (a) Device and specimen used for tensile loading and (b) device and specimen used for compression loading.

\subsection{Shear tests with the modified TAST}

The thick adherend shear test (TAST) can be considered to be an optimized single lap shear test and is widely used to evaluate mechanical adhesive properties $[10,17]$. The test is detailed in standards ISO 11003-2 and ASTM D3983. It has been shown that for such tests, cracks can appear quickly at the two edges of the adhesive joint, close to the adhesive-substrate interfaces [17-18]. In order to improve this test, a modified TAST fixture has been proposed [16]. This fixture is presented in Fig. 3. It uses small bonded samples (Fig. 3) which represent the useful part of the TAST specimen (a parallelepiped of height approximately $20 \mathrm{~mm}$ with an adhesive section $S c=9.53 \mathrm{~mm} \times 25.4 \mathrm{~mm}$ ), a rigid support (2) and a fastening device (3). A special system was used (noted (4) in Fig. 3) to obtain precise positioning of the specimen in the support. A special fixing arrangement (presented in the previous section) was 
used to connect the modified TAST fixture to the tensile testing machine in order to prevent parasitic loads during the different phases of the test. The main parameters which define the geometry of the bonded specimen are: $2 e=0.2 \mathrm{~mm}, h=0.2 \mathrm{~mm}, d=0.5 \mathrm{~mm}, \rho=1.5 \mathrm{e}, \beta=60^{\circ}$ (Fig. 3c). For these tests, the displacement rate of the crosshead of the tensile testing machine was $0.024 \mathrm{~mm} / \mathrm{minute}$.

Each test on a bonded assembly requires nearly two hours, taking into account the preparation phases, closure of the vessel, increasing of the pressure, and the mechanical loading at a slow crosshead displacement rate of the tensile testing machine, followed by opening of the vessel.

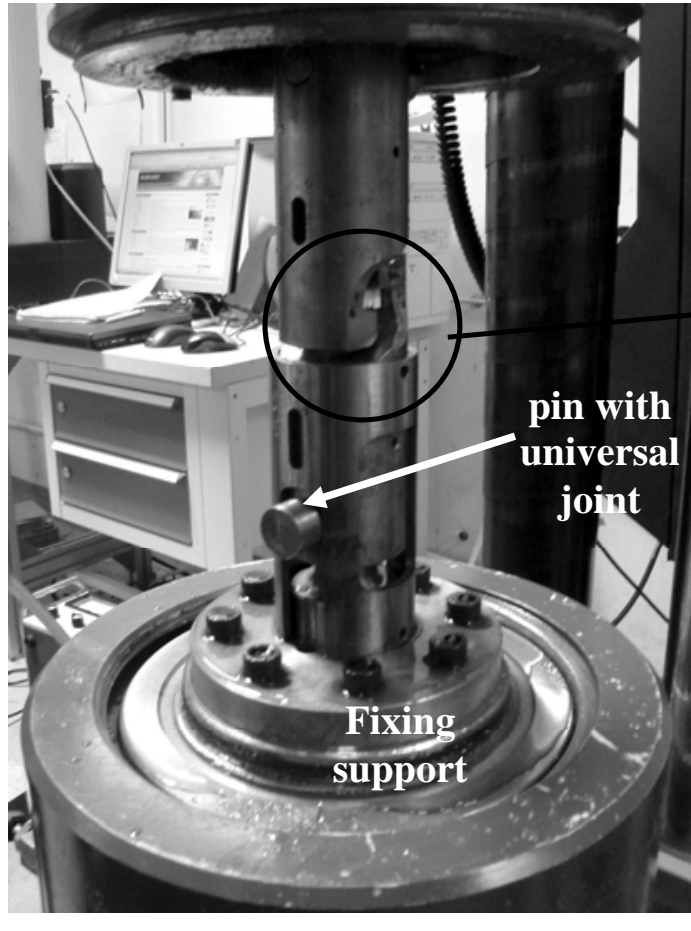

(a)

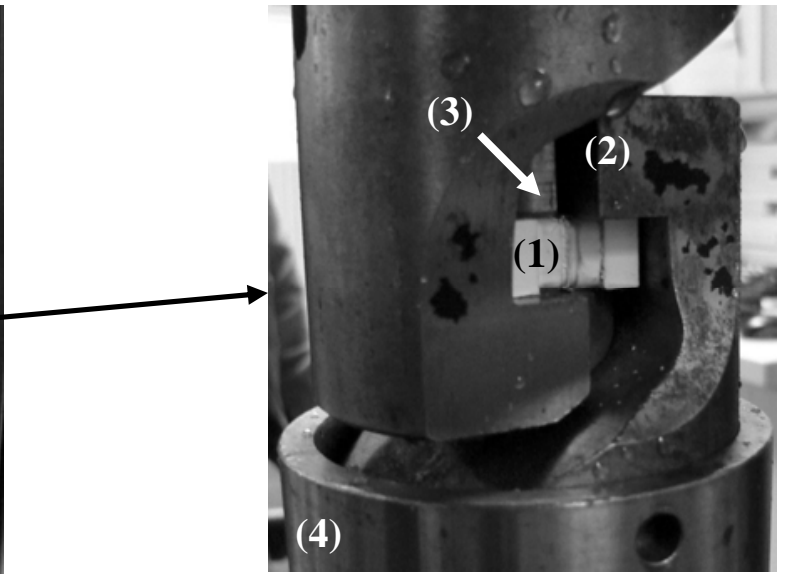

(b)

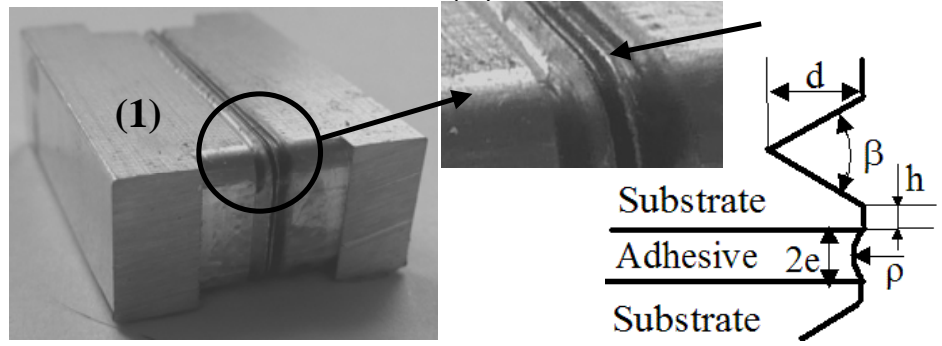

(c)

FIGURE 3 Modified TAST in the pressure vessel. (a) Mounting of the device, (b) fixing of the bonded specimen and (c) geometry of the small bonded specimen with beaks all around the substrates.

In order to choose the geometry of the bonded specimens, 3D models were used to analyze the influence of the hydrostatic pressure on the stress distribution in the adhesive. To limit the size of the numerical model, the calculation was made on a quarter of the TAST specimen, using adequate boundary conditions (Fig. 4a). Figures 4a-b present geometries of two bonded specimens for the modified TAST device. The first one has a rectangular shape and the adhesive free edges are straight (Fig. 4a). The second one has a round shape, with beaks all around the substrates and the adhesive free edges (borders of the joint) are cleaned by wiping off excess adhesive (Fig. 4b). In fact, as the computations were performed under elastic assumptions for the different parts, the influence of the hydrostatic pressure on the stress distribution in the adhesive can be seen as the superposition of two loadings. The first is associated with pressure on the substrate surfaces whose normal direction is parallel to the normal of the joint mean plane (coordinate z, Fig. 4a). Such loading leads to a compression of the joint between the two substrates. Therefore the numerical results obtained for the modified Arcan system under tensile loading can be used; they underline that beaks all around the substrates are necessary to limit the influence of edge effects [19]. The second loading component is associated with pressure on the other surfaces of the bonded joint (surfaces presented in grey in Fig. 4a). For such loadings, numerical simulations have been performed using aluminium substrates (Young modulus: $E_{a}=75 \mathrm{GPa}$, Poisson's ratio: $v_{a}=0.3$ ) and the elastic material parameters for the studied 
adhesive were such that: $E_{j}=2.0 \mathrm{GPa}, v_{j}=0.42$ (results obtained from tensile and compression bulk tests). Results are only presented for a small part of the adhesive (close to a so-called corner: circle on Fig. 4a-b). Figure 4c presents the distribution of the von Mises equivalent stress in the adhesive for a pressure of $1 \mathrm{MPa}$ for a joint thickness of $0.2 \mathrm{~mm}$. It can be noted that only a small part of the adhesive close to the joint free edges is loaded, and such a geometry leads to quite large stress concentrations close to the substrate-adhesive interface. Figures $4 \mathrm{~d}-\mathrm{f}$ present the distribution of the von Mises equivalent stress in the adhesive for geometry " $\mathrm{b}$ " for a pressure of $1 \mathrm{MPa}$ and for joint thicknesses of $0.2,0.4$ and $0.8 \mathrm{~mm}$. Under each drawing, the minimal and maximal values of the von Mises equivalent stress is written. This indicates that in order to limit the stress concentrations, it is necessary to use thin joints. Experimental tests were performed using an adhesive thickness of $0.2 \mathrm{~mm}$ in order to facilitate the measurement of the adhesive deformation in the pressure vessel through the view-glass. Moreover, the use of thin beaks and joint edges from which spew fillets are removed give good results for the loading associated with the hydrostatic pressure and for the mechanical loading.

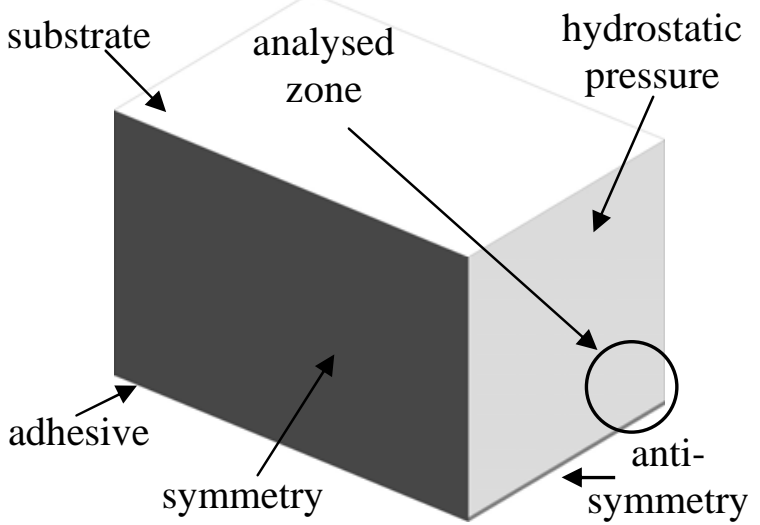

(a)

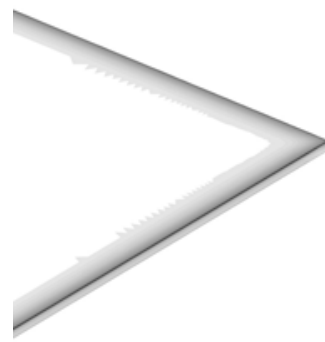

$\geq 0 \leq 2.45$

(c)
2.5

2.0

1.5

$1.0 \mathrm{z}$

0.5

0.0

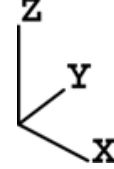

von Mises stress

(MPa)

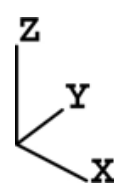

(b)
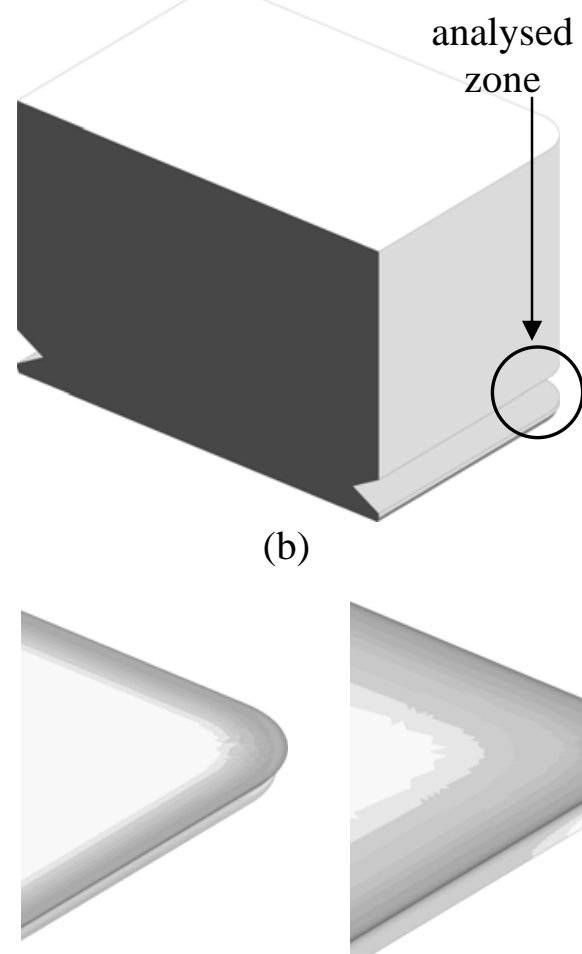

$\geq 0 \leq 1.16$

(e)

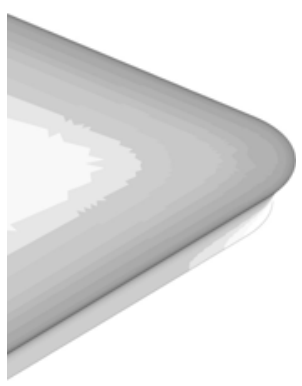

$\geq 0 \leq 1.32$

(f)

FIGURE 4 Influence of the hydrostatic pressure on the stress distribution in the adhesive for the modified TAST specimen. (a) Quarter of the bonded specimen with a rectangular shape and with straight edges of the adhesive free edges (b) quarter of the bonded specimen with a round shape, beaks all around the substrates and cleaned edges of the adhesive free edges, (c) von Mises equivalent stress in the adhesive for geometry "a" for a pressure of $1 \mathrm{MPa}$ for a joint thickness of $0.2 \mathrm{~mm}$, (d) von Mises equivalent stress in the adhesive for geometry "b" for a pressure of $1 \mathrm{MPa}$ for a joint thickness of 0.2 $\mathrm{mm}$, (e) von Mises equivalent stress in the adhesive for geometry "b" for a pressure of $1 \mathrm{MPa}$ for a joint thickness of $0.4 \mathrm{~mm}$ and von Mises equivalent stress in the adhesive for geometry " $\mathrm{b}$ " for a pressure of $1 \mathrm{MPa}$ for a joint thickness of $0.8 \mathrm{~mm}$. 


\subsection{Tensile-shear test with the modified Arcan device}

In order to develop an accurate model of the non-linear behaviour of the adhesive in a bonded assembly, it is important to analyse the influence of the peel stress. A modified Arcan fixture, which enables compression or tension to be combined with shear loads has been developed previously [11]. By the use of beaks, careful cleaning of the free edges of the adhesive, and by designing a special fixing system for the bonded specimen, the edge effects can be significantly reduced, and pre-loading of the adhesive is avoided (Fig. 5) [11, 19]. The limited space inside the pressure vessel has required the design and manufacture of a small Arcan fixture (external diameter of $155 \mathrm{~mm}$ ). In order to be compatible with the water used to generate the hydrostatic pressure, the device was made of stainless steel. Special fixing similar to that used for the other tests were used to fix the modified Arcan device in order to prevent parasitic loadings. Substrates with thin beaks all around were used (geometry similar to the modified TAST specimens) and bonded specimens with a rectangular section (10 mm $\mathrm{x}$ $50 \mathrm{~mm}$ ) were tested. For these tests, the displacement rate of the crosshead of the tensile testing machine was $0.024 \mathrm{~mm} /$ minute. In the case of linear elastic behaviour, the stress distribution is not constant in the adhesive for the modified Arcan test, thus, inverse identification techniques was used in order to analyse the experimental results [12].

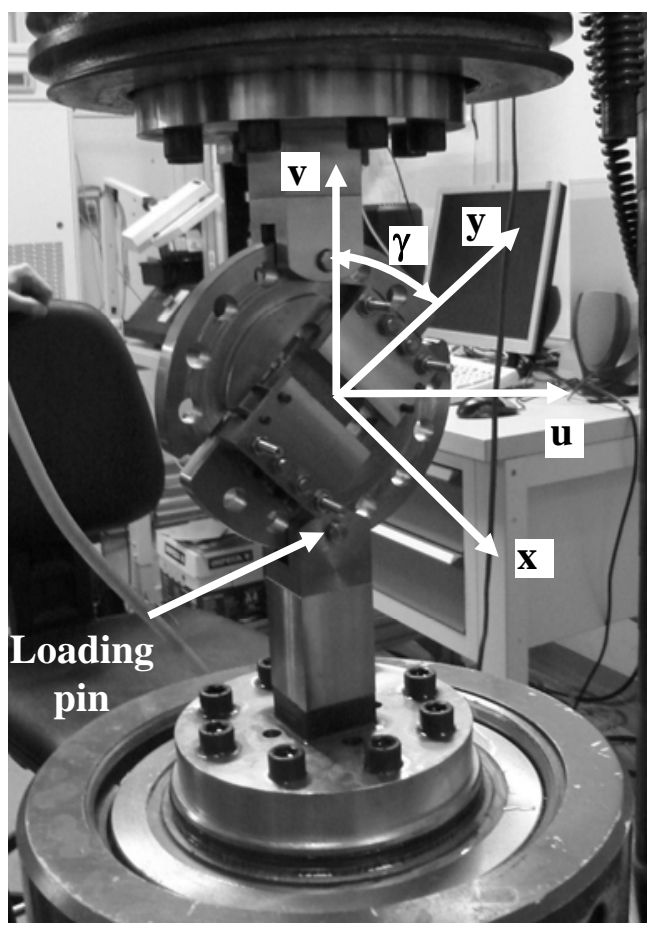

test with $\gamma=45^{\circ}$

(a)

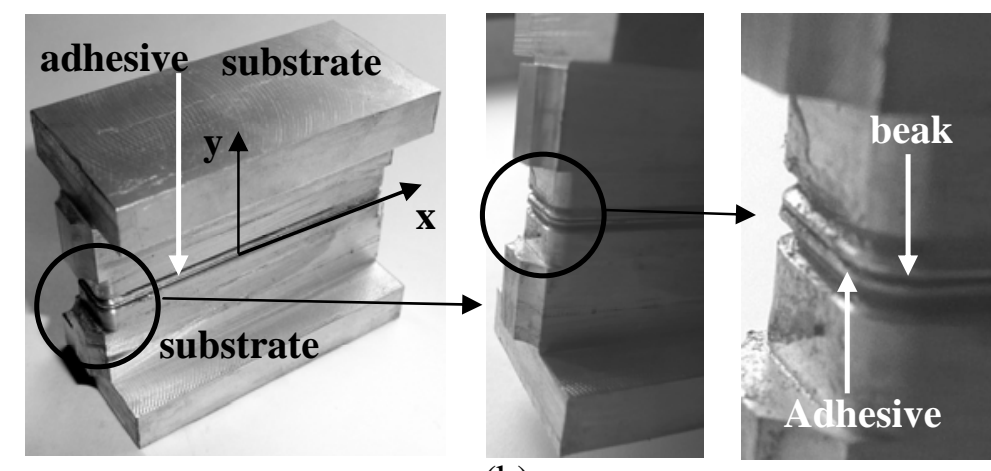

(b)

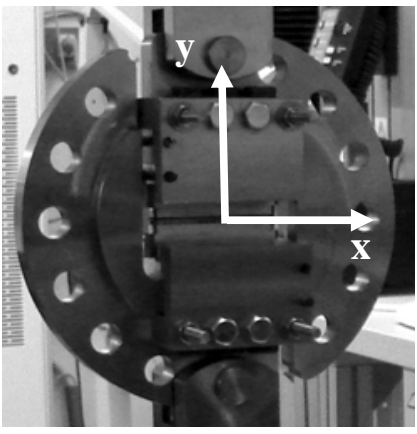

test with $\gamma=0^{\circ}$

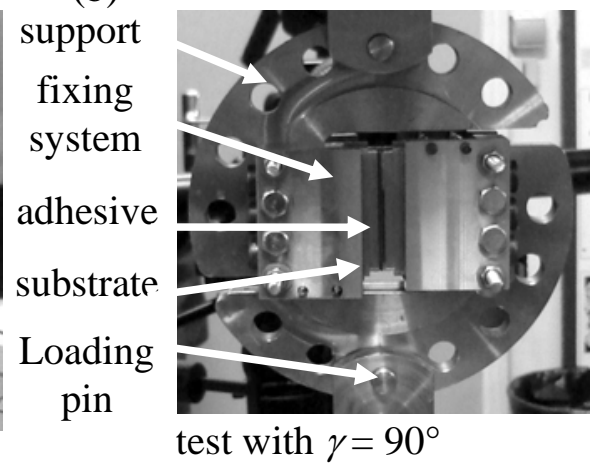

(c)

FIGURE 5 Modified Arcan device in the pressure vessel. (a) Test under tensile-shear loading $\gamma=45^{\circ}$, (b) presentation of the bonded specimen \& close-up view of the beak and (c) test under tensile loading $\gamma=0^{\circ}$ and test under shear loading $\gamma=90^{\circ}$.

\section{Influence of the hydrostatic stress on the initial yield function}

This section presents, for various mechanical loadings, the influence of the hydrostatic pressure on the mechanical non-linear behaviour of an adhesive in bulk specimens and in assemblies. For the different experimental tests, the strain was analysed using an image correlation technique. As the stress state is quite complex in the adhesive for the bonded assemblies (modified TAST and Arcan test), in the 
following a simplified approach is used in order to determine different points of the initial yield function.

\subsection{Experimental results for the adhesive in bulk}

The experimental conditions which have been chosen to obtain a constant strain rate in the adhesive for the different tests lead to some difficulties for the bulk adhesive tests. On one hand, as the displacement rate of the cross head of the tensile testing machine is quite large, the specific two-chamber equilibrium system of the pressure vessel can lead to a little over-estimation of the transmitted load. And on the other hand, for the tensile tests, the transmitted load is quite low compared to the capacity of the tensile load sensor.

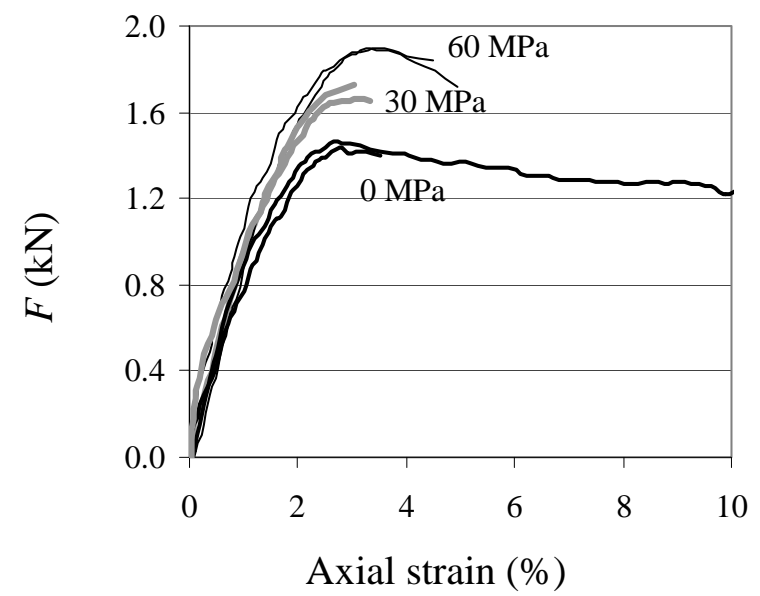

FIGURE 6 Load-strain curves for tensile tests on bulk specimens for a crosshead displacement rate $V$ $=5 \mathrm{~mm} / \mathrm{min}$ and for pressures $p=0,30,60$ and $90 \mathrm{MPa}$.

Figure 6 presents the experimental results for the bulk tensile tests in the load-strain diagram for pressures $p=0,30$ and $60 \mathrm{MPa}$. For each pressure, tests were performed on four specimens. Figure 6 gives an idea of the scatter in the experimental results; it can be noted that the scatter in the elastic part is quite low.

The experimental results for bulk compression tests are shown in Figure 7. Figure 7a presents the time evolution of the load for the four pressures $(0,30,60$ and $90 \mathrm{MPa})$ and Figure $7 \mathrm{~b}$ presents the loadstrain diagrams for pressures $p=0,30$ and $60 \mathrm{MPa}$. For each pressure, four specimens were used and it can be noted that test variability is again quite low.

Figure 8 presents the elastic part of the results in the von Mises equivalent stress-hydrostatic stress diagram. The dashed lines represent, under elastic behaviour, the loading path in the pressure vessel. For such tests, starting with an unstressed specimen (represented by the mark "О" in Figure 8), an increase in the hydrostatic pressure leads to a decrease in the hydrostatic stress without modifying the zero value of the von Mises equivalent stress. Such a loading is presented in Figure 8 with a grey arrow for a hydrostatic pressure of $60 \mathrm{MPa}$. The different marks " $\boldsymbol{~}$ " represent the stress state for a hydrostatic pressure of 0, 30, 60 and $90 \mathrm{MPa}$. Starting from the mechanical loading associated with a given hydrostatic pressure, the loading path for tensile and compression uniaxal loadings can be easily drawn in this diagram (the difference between tensile and compression is the sign of the uniaxial stress). For a hydrostatic pressure of $60 \mathrm{MPa}$, the loading path for tensile and compression loadings are shown using black arrows. The elastic limit obtained with bulk specimens for the different loadings in the pressure vessel are presented in Figure 8; results for tensile and compression tests are represented

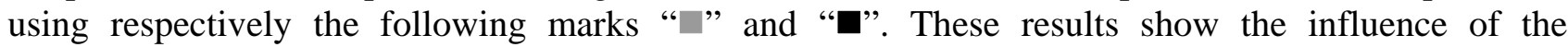


hydrostatic stress on the mechanical behaviour of the adhesive (initial elastic limit for a given strain rate).

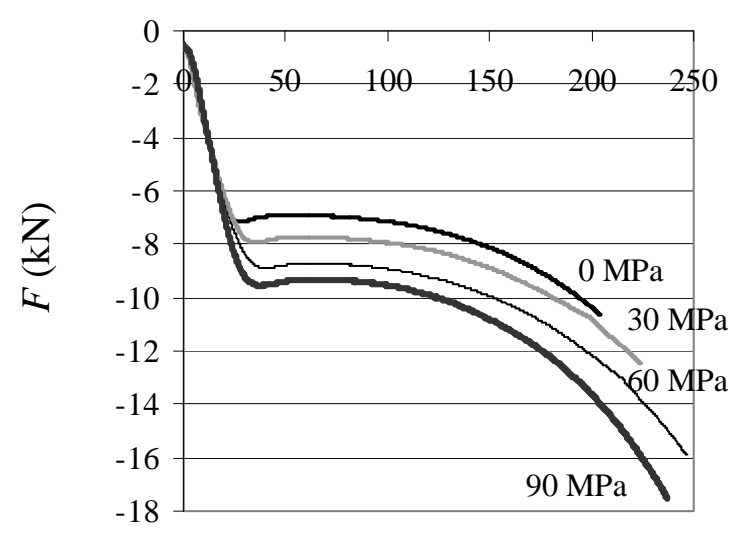

Time (s)

(a)

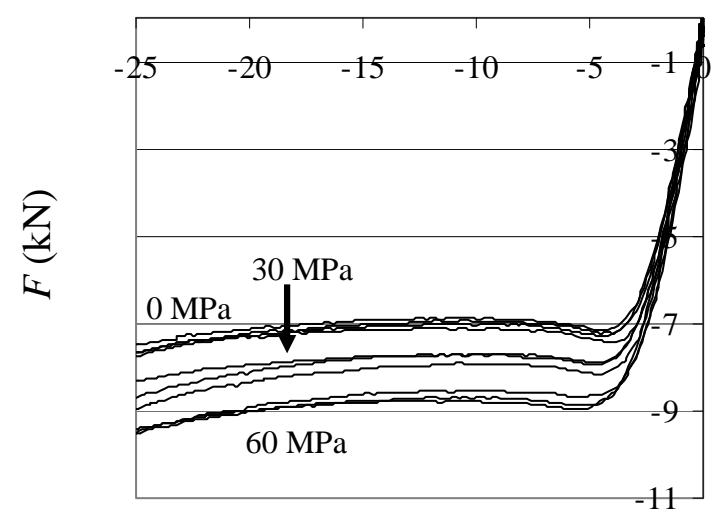

Axial strain (\%)

(b)

FIGURE 7. Experimental results for compression tests on bulk specimens for a crosshead displacement rate $V=3 \mathrm{~mm} / \mathrm{min}$. (a) Load-time diagram for pressures $p=0$, 30, 60 and $90 \mathrm{MPa}$ and (b) load-strain diagram for pressures $p=0,30$ and $60 \mathrm{MPa}$.

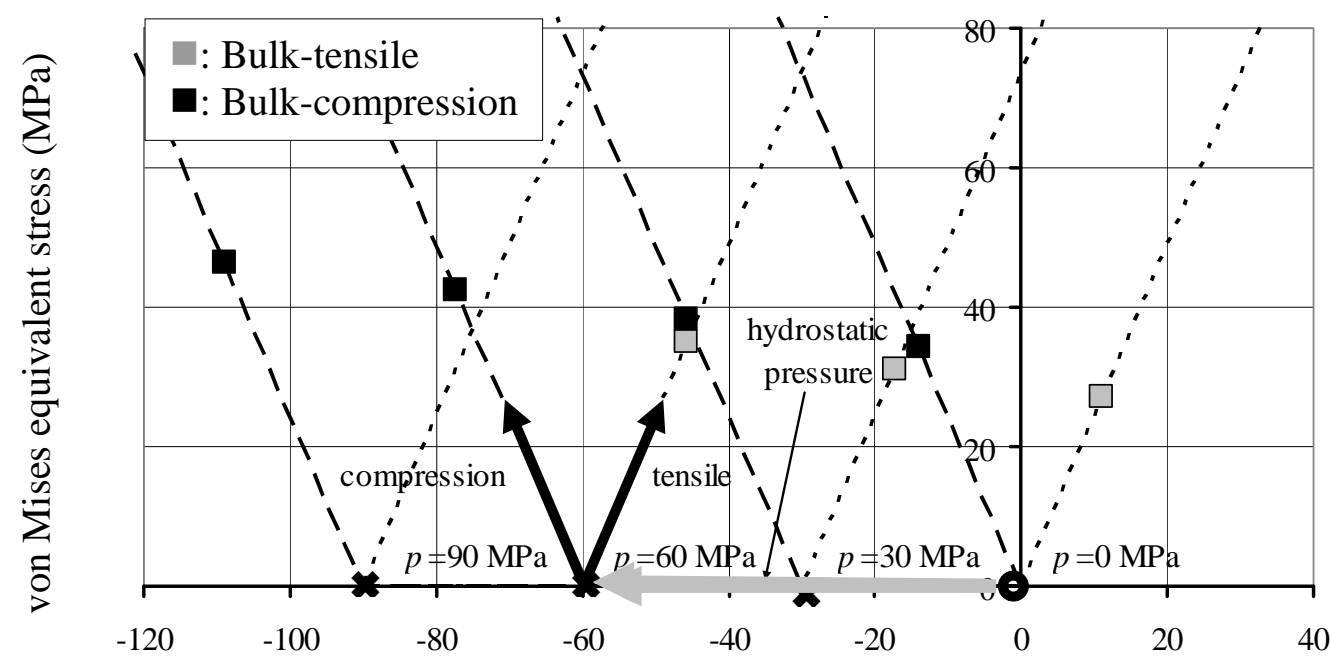

Hydrostatic stress (MPa)

FIGURE 8 Experimental elastic limits for bulk tests, for an axial strain rate of 0.12 minute $^{-1}$ and for 4 loading paths at different pressures $(0,30,60$ and $90 \mathrm{MPa})$; the dashed lines represent, under elastic behaviour, the loading path in the pressure vessel.

\subsection{Experimental results for shear tests with the modified TAST}

For the modified TAST, the term DT denotes the relative displacements of both ends of the adhesive in the tangential direction. FT represents the applied load in the tangential direction in the mean plane of the adhesive.

Figure 9 presents results for three hydrostatic stress loads $(0,30$ and $60 \mathrm{MPa})$ in the load-displacement (FT-DT) diagram and indicates the influence of the hydrostatic stress on the behaviour of the adhesive in a bonded assembly under shear loadings. For a given hydrostatic pressure, two specimens were used. These tests are associated with quite low variability; other results can be found in [13]. 


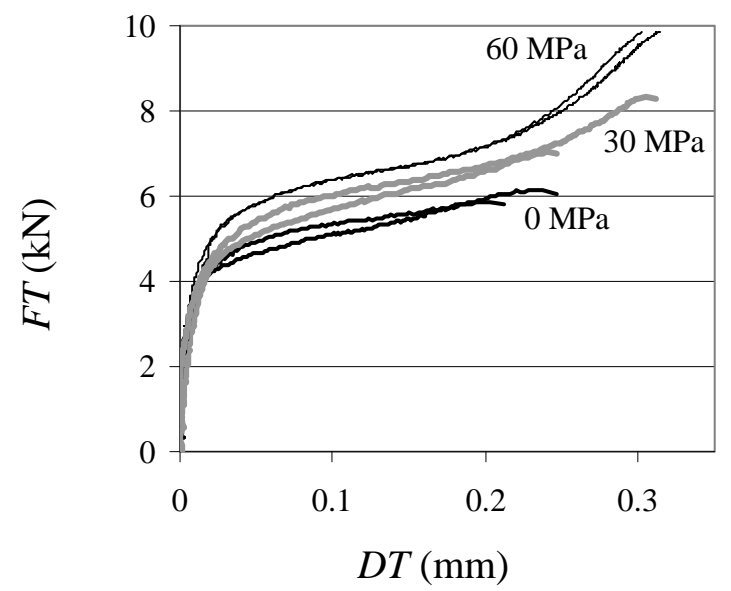

FIGURE 9 Load-displacement curves for shear tests using the modified TAST for a crosshead displacement rate $V=0.024 \mathrm{~mm} / \mathrm{min}$ and for pressures $p=0,30$ and $60 \mathrm{MPa}$.

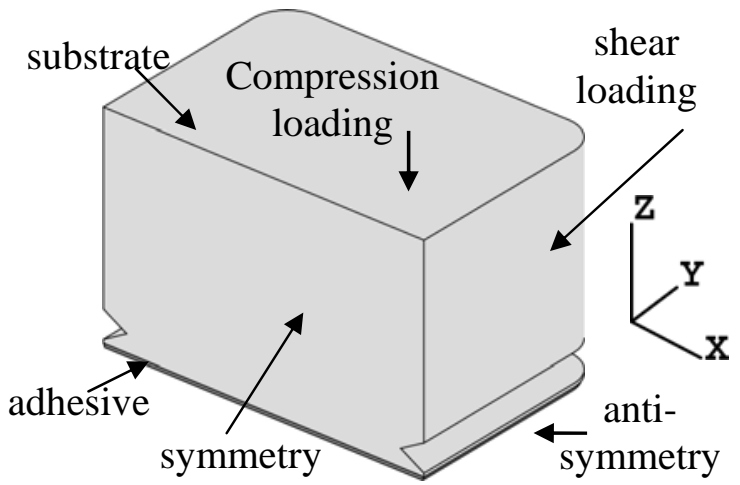

(a)

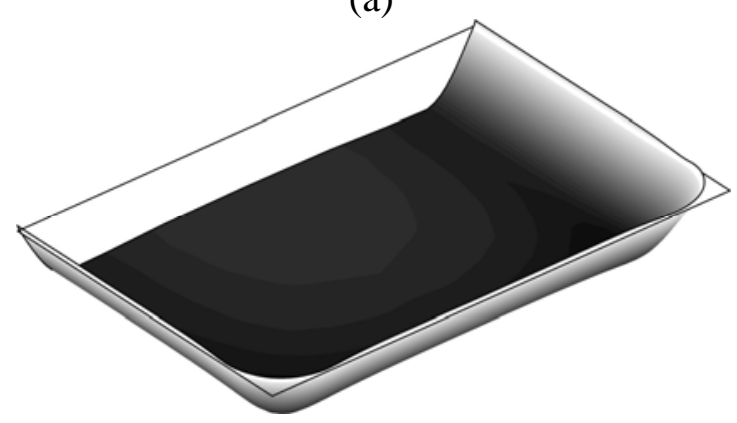

(c)

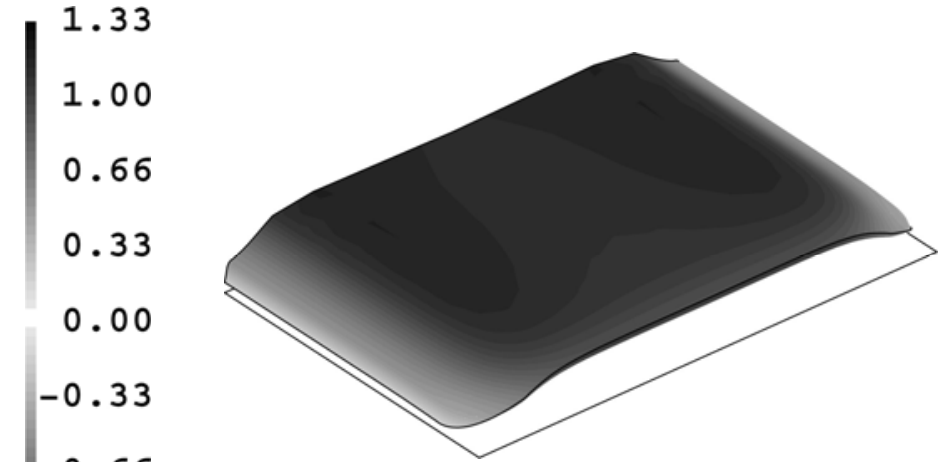

(b)

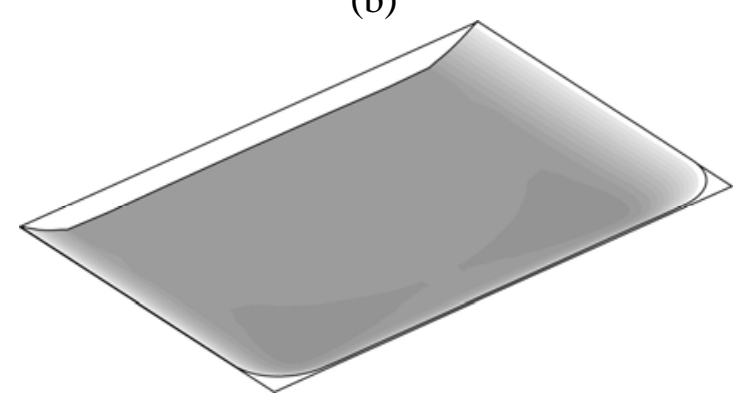

(d)

FIGURE 10 Stress distribution in the mean plane of the TAST joint for compression and shear loadings. (a) Quarter of the bonded specimen with a round shape, beaks all around the substrates and the adhesive free edges cleaned, (b) shear stress in the mean plane of the adhesive for an average shear stress of 1 $\mathrm{MPa}$, (c) tensile stress in the $\mathrm{z}$ direction in the mean plane of the adhesive for an average tensile stress of $1 \mathrm{MPa}$ associated with compression in the $\mathrm{z}$ direction, and (d) tensile stress in the y direction in the mean plane of the adhesive for an average tensile stress of $1 \mathrm{MPa}$ associated with compression in the $\mathrm{z}$ direction.

An analysis of the stress distribution in the adhesive, for this shear test in the pressure vessel, requires two main mechanical loadings to be taken into account. A compression of the bonded joint associated with the hydrostatic pressure, and a shear loading associated with the mechanical loading. Figure 10a presents the geometry of the modified TAST bonded specimen with a round shape, beaks all around the 
substrates and the adhesive free edges cleaned. For the two computations under elastic assumptions, a quarter of the specimen can be used using adequate boundary conditions (Fig. 10a). Figure 10b shows the shear stress on half of the mean plane of the adhesive for an average shear stress equal to $1 \mathrm{MPa}$. The shear stress is represented on the $z$-axis and the maximal value of the shear stress is equal to 1.16. For the compression loading in the $\mathrm{z}$ direction, Figure 10c- $d$ present respectively the tensile stress in the $\mathrm{z}$ and $\mathrm{y}$ directions for an average tensile stress in the $\mathrm{z}$ direction equal to 1 . The ratio of the maximal and the average $\mathrm{zz}$ component of the tensile stress is equal to 1.30. In the middle of the joint the ratio of the $\mathrm{xx}$ or yy component and the zz component stress is equal to 0.70 . In the following, a simplified analysis of such tests is proposed using the stress state in the middle of the adhesive.

It can be noted that such geometries of the bonded specimens limit the stress state close to the free edges of the adhesive, even using hydrostatic pressure. The normal components of the stress are very low all around the free edge of the joint; but the shear stress is only very low on two of the free edges of the bonded joint.

Figure 11 presents the elastic part of the results in the von Mises equivalent stress-hydrostatic stress diagram. The dashed lines represent, under elastic behaviour, the loading path in the pressure vessel. For such tests, starting with an unstressed specimen, increasing the hydrostatic pressure leads to compression of the bonded specimen which can be described using the previous numerical results. Such a loading is presented in Figure 10 with a grey arrow for a hydrostatic pressure of $60 \mathrm{MPa}$. For a given hydrostatic pressure, the mechanical shear loading is associated with an increase of the von Mises equivalent stress (shown using a black arrow for a pressure of $60 \mathrm{MPa}$ ). The different points of the elastic limit are presented in Figure 10 using the following marks " $\boldsymbol{\Delta}$ ”.

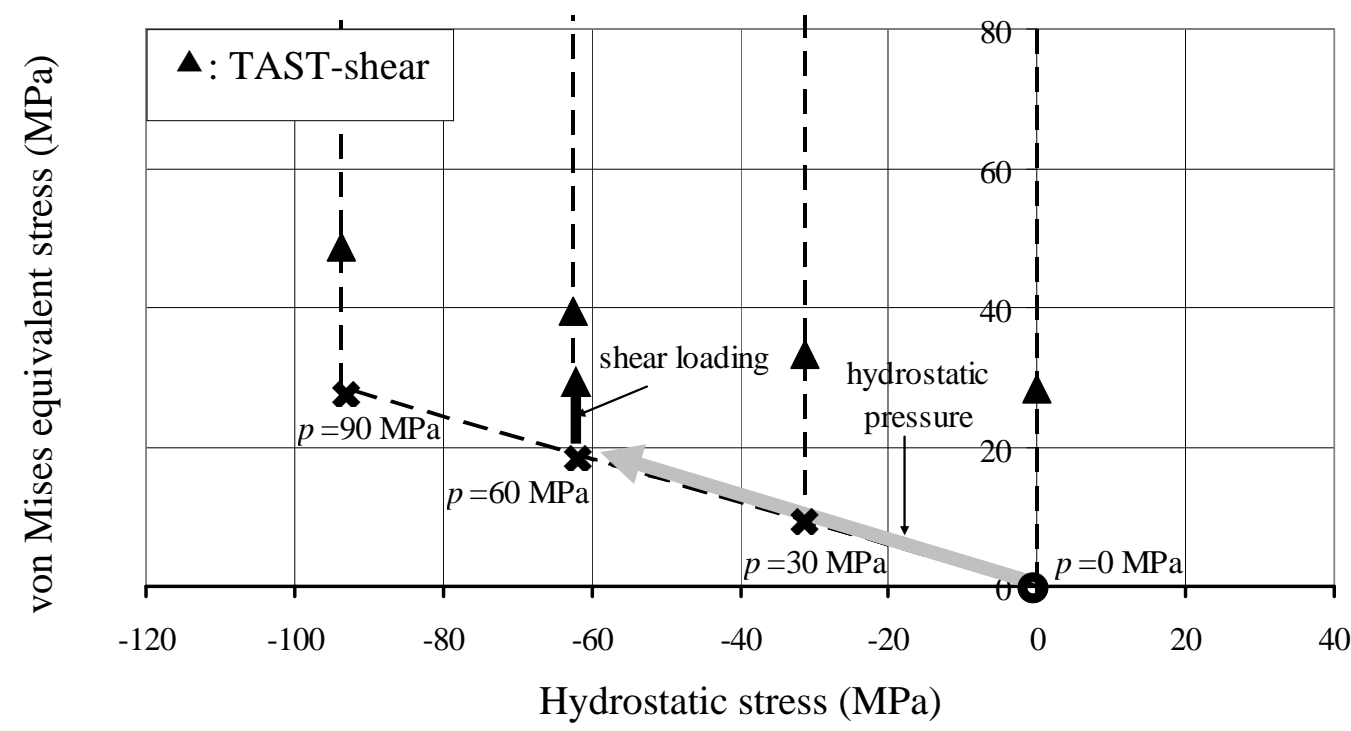

FIGURE 11 Experimental elastic limits for modified TAST tests, for a displacement rate of the tensile machine crosshead $V=0.024 \mathrm{~mm} / \mathrm{min}$ and for 4 loading paths at different pressures $(0,30,60$ and 90 $\mathrm{MPa}$ ); the dashed lines represent, under elastic behaviour, the loading path in the pressure vessel.

\subsection{Experimental results for tensile-shear tests with the modified Arcan device}

For each given hydrostatic pressure, and for each configuration of the Arcan device studied ( $\gamma=0,45$, 90 and $135^{\circ}$ ) only one specimen was used, as each test requires nearly 2 hours. The scatter in the results are very low for the modified Arcan tests as for this test the influence of edge effects is strongly limited using beaks and cleaning of the adhesive free edges $[11,17]$. For the Arcan tests, the terms $D N$ and $D T$ denote the relative displacements of both ends of the adhesive in the normal (direction $\mathrm{y}$, 
Figure 5) and tangential direction (direction $\mathrm{x}$, Figure 5). FN and FT represent the normal and tangential components of the applied load in the normal and tangential directions.

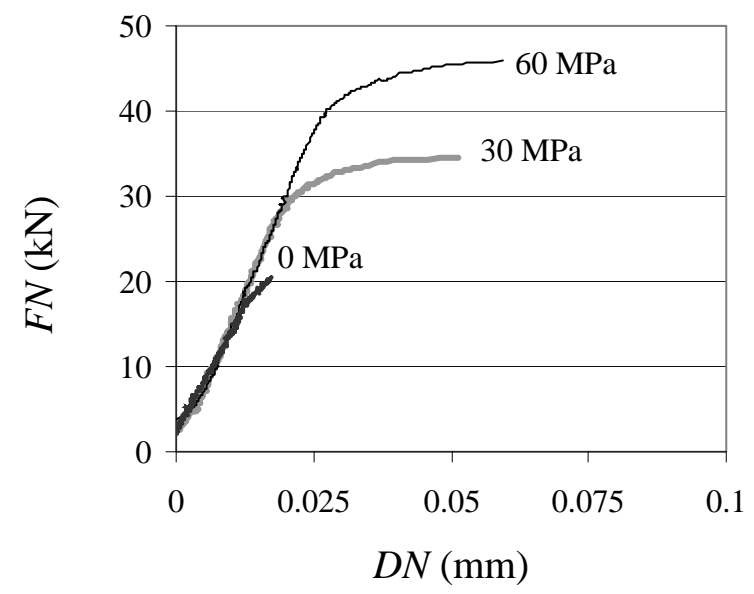

FIGURE 12 Experimental results for tensile tests with the modified Arcan device $\left(\gamma=0^{\circ}\right)$ for pressures $p=0,30$ and $60 \mathrm{MPa}$ for a crosshead displacement rate $V=0.024 \mathrm{~mm} / \mathrm{min}$.

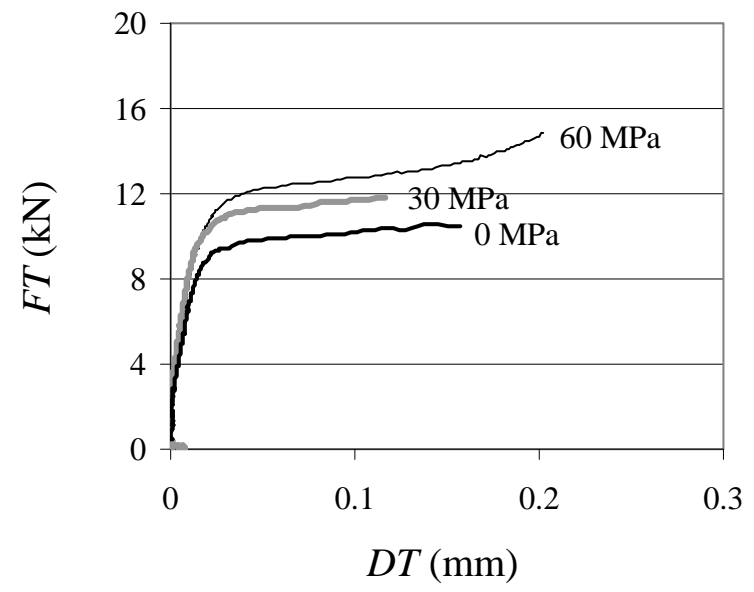

(a)

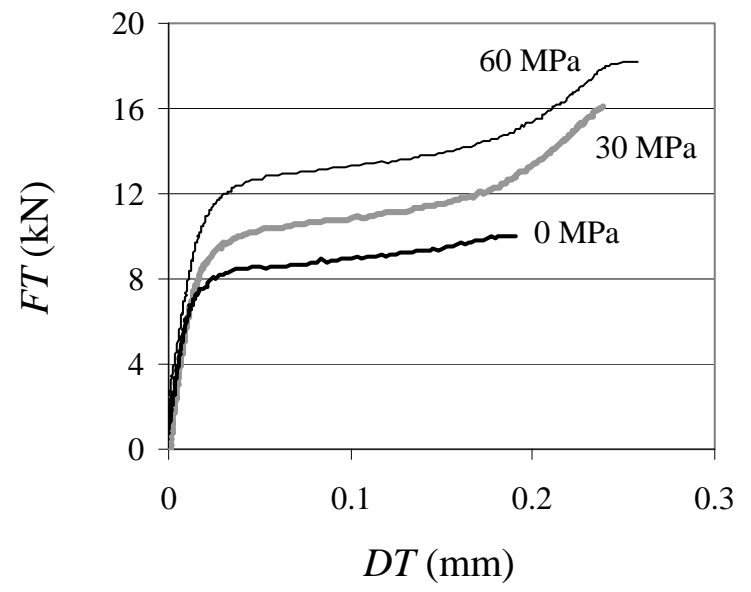

(b)

FIGURE 13 Experimental results for tests with the modified Arcan device for pressures $p=0,30,60$ and $90 \mathrm{MPa}$ for a crosshead displacement rate $V=0.024 \mathrm{~mm} / \mathrm{min}$. (a) Results for tensile-shear $(\gamma=$ $45^{\circ}$ ), and (b) results for shear loadings $\left(\gamma=90^{\circ}\right)$.

Experimental results using the modified Arcan fixture are presented for three hydrostatic stress levels $(0,30$ and $60 \mathrm{MPa})$ in Figures $12-14$. Figure 12 presents results of tensile tests $\left(\gamma=0^{\circ}\right)$ in the loaddisplacement $(F N-D N)$ diagram (results in the normal direction). Figure 13 shows results from tensileshear $\left(\gamma=45^{\circ}\right)$ and shear tests $\left(\gamma=90^{\circ}\right)$ on the load-displacement (FT-DT) diagram (results in the tangential direction). Results under tensile shear loadings $\left(\gamma=135^{\circ}\right)$ are presented in Figure 14 on a load-time diagram; for these tests the load $F$ measured by the tensile testing machine is presented (combination of FN and FT).

Figure 15 presents the elastic part of the results in the von Mises equivalent stress-hydrostatic stress diagram. The elastic limits obtained for the tensile and shear loadings are presented using respectively the following marks "•" and "॰". For the two tests the initial loading with the hydrostatic pressure is represented as a compression of the bonded assembly as for the modified TAST. For shear tests the stress path is similar to the one obtained with the modified TAST specimen. However, for tensile tests, the loading of the tensile testing machine leads first to a reduction in the compression of the bonded 
assembly, and secondly to a tensile loading of the specimen. The arrows indicate the loading path of the bonded joint for a pressure of $30 \mathrm{MPa}$.

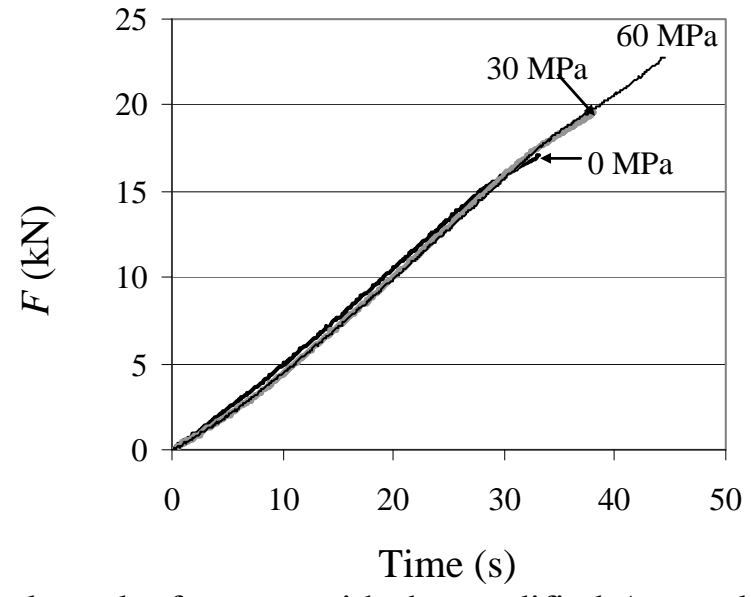

FIGURE 14 Experimental results for tests with the modified Arcan device for pressures $p=0$, 30 and $60 \mathrm{MPa}$ for a crosshead displacement rate $V=0.024 \mathrm{~mm} / \mathrm{min}$ - compression-shear tests $\left(\gamma=135^{\circ}\right)$.

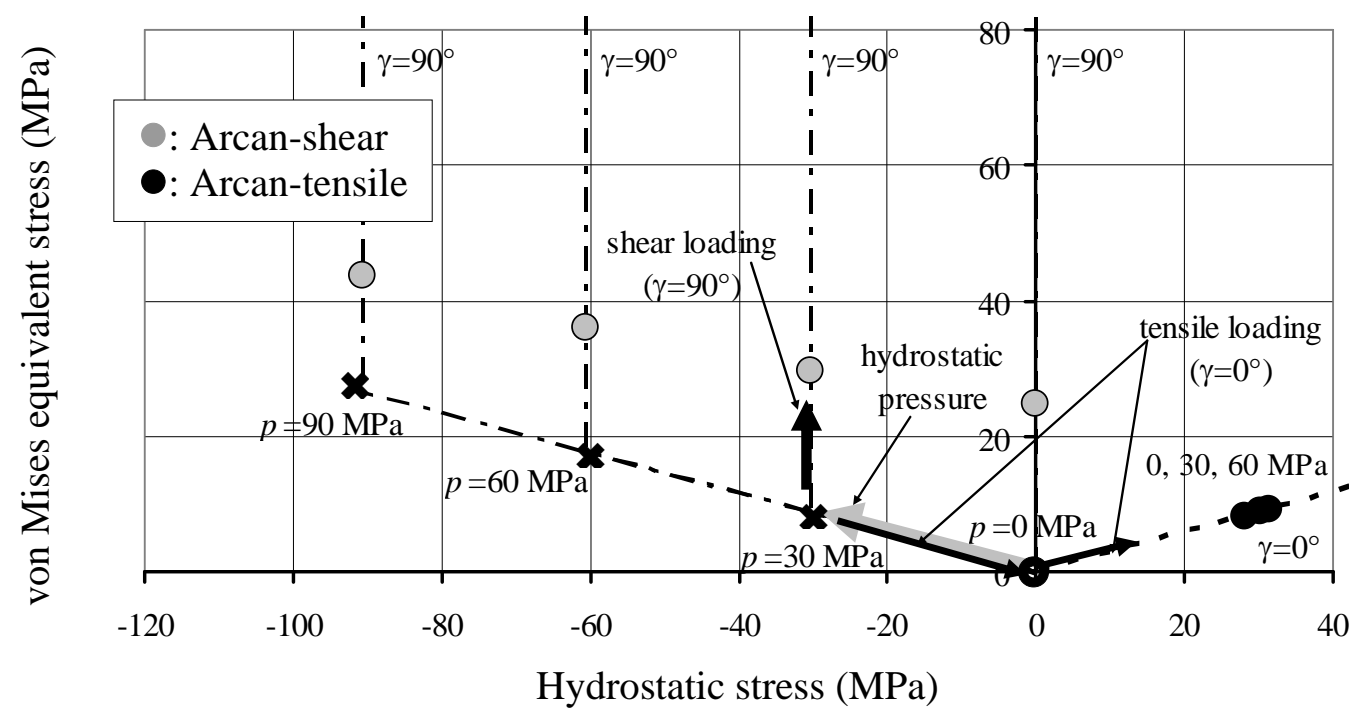

FIGURE 15 Experimental elastic limits for modified Arcan tests $\left(\gamma=0^{\circ}, 90^{\circ}\right)$, for a displacement rate of the tensile machine crosshead $V=1 \mathrm{~mm} / \mathrm{min}$ and for 4 loading paths at different pressures $(0,30,60$ and $90 \mathrm{MPa}$ ); the dashed lines represent, under elastic behaviour, the loading path in the pressure vessel.

Results under tensile-shear and compression-shear loads are presented in Figure 16 using respectively the following marks "»" and "»". The dashed lines represent, under elastic behaviour, the loading path in the pressure vessel. It can be noticed that for such tensile-shear tests the loading path is more complex that for tensile or shear tests. 


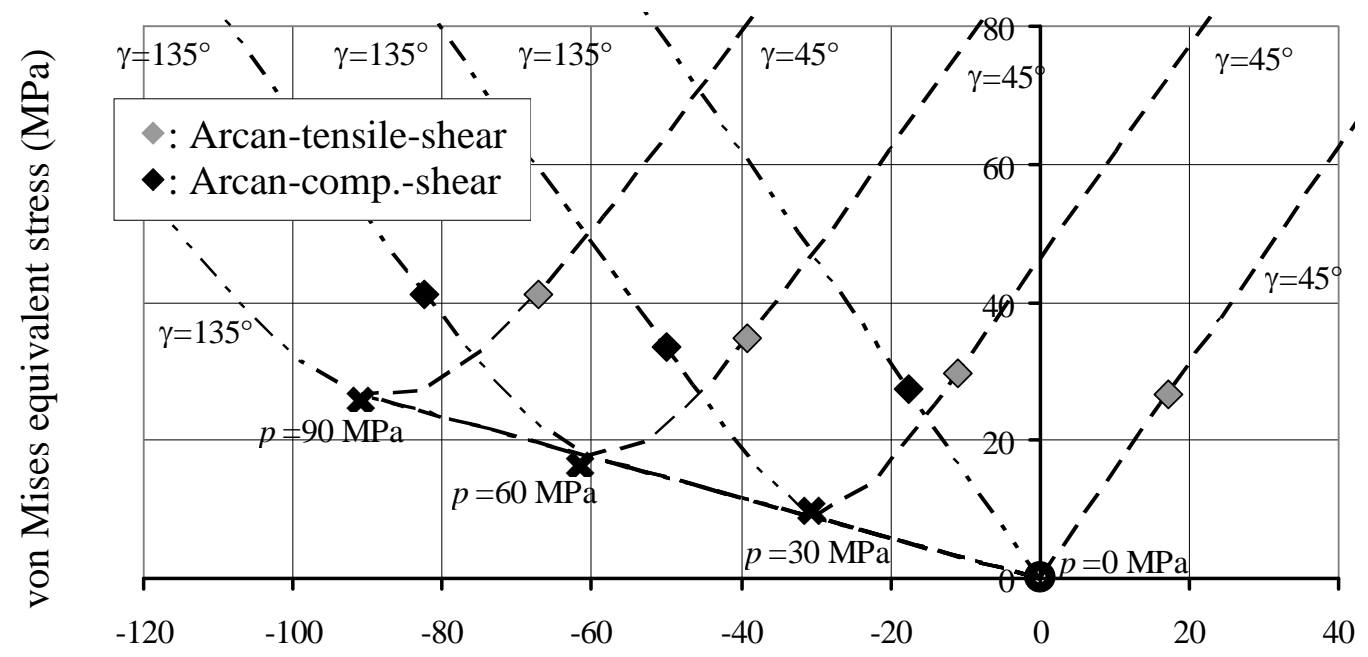

Hydrostatic stress (MPa)

FIGURE 16 Experimental elastic limits for modified Arcan tests $\left(\gamma=45^{\circ}, 135^{\circ}\right)$, for a displacement rate of the tensile machine crosshead $V=1 \mathrm{~mm} / \mathrm{min}$ and for 4 loading paths at different pressures $(0$, 30, 60 and $90 \mathrm{MPa}$ ); the dashed lines represent, under elastic behaviour, the loading path in the pressure vessel.

\subsection{Comparison of the different experimental results}

The different experimental points of the so-called initial elastic limit of the studied adhesive for an axial strain rate of 0.12 minute $^{-1}$, obtained with the different mechanical tests using different hydrostatic pressures $(0,30,60$ and $90 \mathrm{MPa})$ in the pressure vessel are plotted in the von Mises equivalent stresshydrostatic stress diagram in Fig. 17. The results, associated with different loading paths of the adhesive, underline a strong influence of the hydrostatic stress on the mechanical behaviour of the adhesive (initial elastic limit for a given strain rate). The pressure vessel allows us to analyse the influence of a large negative hydrostatic stress. Results obtained on bulk specimens (under tensile or compression loadings) are quite similar to those obtained with bonded specimens with the modified TAST and the modified Arcan device. The scatter in the results, with various tests and using the pressure vessel is quite low; but test variability for tensile tests on bulk specimens is larger than for the other used tests.

The specific two-chamber equilibrium system of the pressure vessel can lead to a little over-estimation of the transmitted load, both for a large displacement rate of the crosshead and for large hydrostatic pressures. Thus, the development of a load sensor placed inside the pressure vessel should improve the experimental results (this is currently being developed).

An exponential Drucker-Prager yield function $\left(F_{0}=0\right)$ allows quite a good representation of the experimental data for the initial elastic limit:

$$
F_{0}=a\left(\sigma_{v m}\right)^{b}+p_{h}-p_{t 0}=0
$$

where $\sigma_{v m}$ is the von Mises equivalent stress and $p_{h}$ is the hydrostatic stress, $a, b$ and $p_{t 0}$ are material parameters. The results of an identification, taking into account the little over-estimation of the transmitted load especially for large hydrostatic pressures, are presented in Table 1 and the initial yield surface is drawn in Figure 17. 


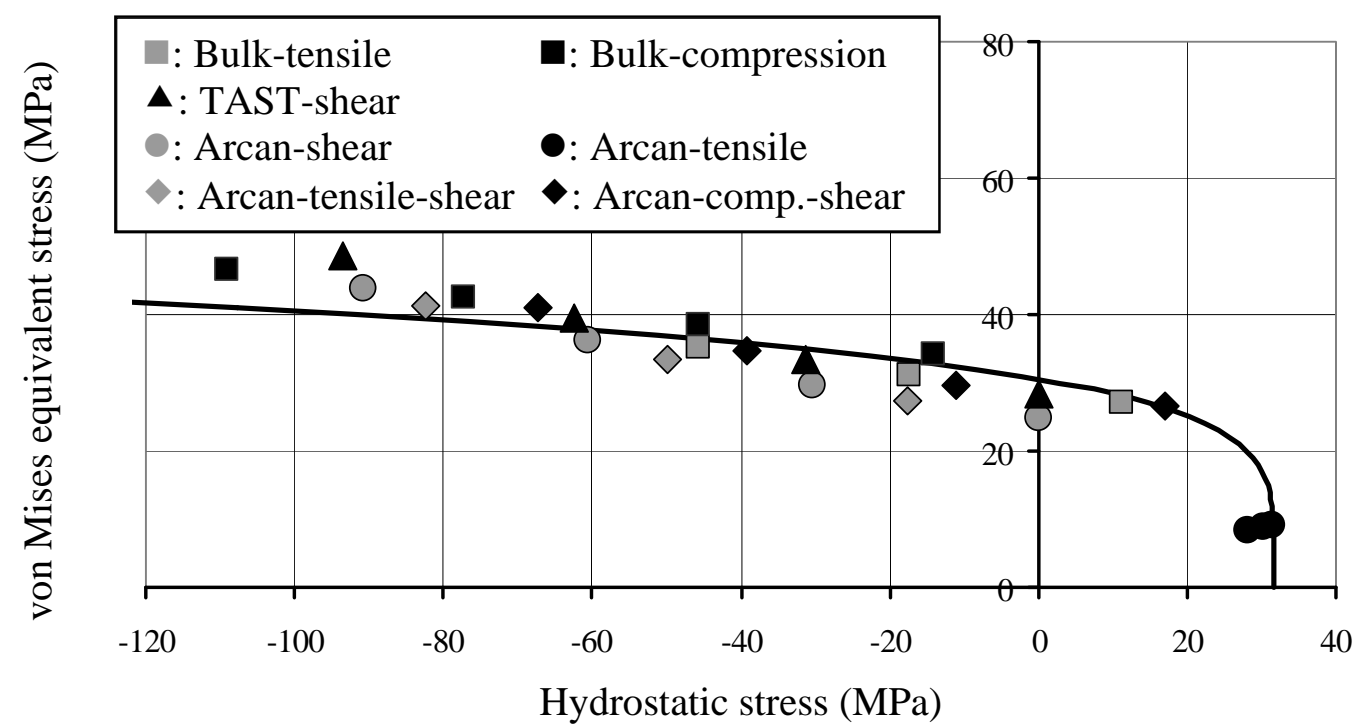

FIGURE 17 Experimental elastic limit in the von Mises equivalent stress-hydrostatic stress diagram for different tests in the pressure vessel for an axial strain rate of 0.12 minute $^{-1}$. The solid line is a representation of the initial elastic limit using an Exponential Drucker-Prager yield function.

TABLE 1 Material parameters for the initial yield surface (defined by the Equation (1)).

\begin{tabular}{|c|c|c|}
\hline$a$ (SI units) & $b$ & $p_{t 0}(\mathrm{MPa})$ \\
\hline $1 . \mathrm{E}-6$ & 5.05 & 31.7 \\
\hline
\end{tabular}

\section{Conclusion}

A pressure vessel combined with a testing tensile machine (the CHEM system) has been used to analyse the influence of hydrostatic stress on the mechanical behaviour of an adhesive. Various tests have been used on both bulk adhesive specimens and bonded assemblies (which strongly limit the influence of the edge effects). This vessel allows pressures up to $100 \mathrm{MPa}$ to be applied during mechanical loading. Thus, the pressure vessel allows various loading paths to be examined using only one mechanical test, under hydrostatic pressure up to $100 \mathrm{MPa}$. For the initial elastic limit and a given strain rate, results obtained with bulk specimens (under tensile or compression loadings) are quite similar to those obtained with bonded specimens using the modified TAST and the modified Arcan device. The results, associated with different loading paths of the adhesive underline a strong influence of the hydrostatic stress on the mechanical behaviour of the adhesive. Moreover, experimental results using bonded specimens allow to analyse the non-linear response of an adhesive using various loading paths, and in particular for large negative hydrostatic stresses. These results constitute a large experimental database, which is essential in order to define accurate models for the mechanical behaviour of an adhesive in an assembly using pressure dependent constitutive laws.

In order to increase the precision of experimental results, a loading sensor placed in the pressure vessel has been developed and is now being evaluated. As the stress state in an adhesive joint is quite complex, inverse identification techniques using 3D finite element models are necessary to accurately analyse the experimental results. Moreover, an optimisation of the geometry of the bonded joint can be done to improve the tests in the pressure vessel: the aim is to limit the stress concentrations close to the free edges of the joint taking into account the hydrostatic pressure and the mechanical loading. 


\section{Acknowledgements}

The authors wish to acknowledge METRI-2 European project for financial support. The authors are grateful to Bernard Leilde, Albert Deuff, Christophe Peyronnet and André Kerboul from IFREMER for their collaboration in the experimental tests with the CHEM system. The authors also thank particularly Hervé Trébaol, Pierre Martinat and Bruno Mecucci from ENSIETA/DTN/CMA for their collaboration in designing and manufacturing the fixing system for bulk tensile tests and the modified Arcan fixture which have been specially designed to be used in the CHEM pressure vessel.

\section{References}

[1] da Silva, L. F. M. and Öchsner, A., Modeling of Adhesive Bonded Joints, (Springer, Heidelberg, 2008).

[2] Adams, R. D., Adhesive Bonding: Science, Technology and Applications, (Woodhead Publishing Limited, England, 2005).

[3] Volkersen, O., Luftfahrtforschung 15, 41-47 (1938).

[4] Adams, R. D., Comyn, J. and Wake, W. C., Structural Adhesive Joints in Engineering, (2nd ed., Chapman \& Hall, London, 1997).

[5] Drucker, D. C. and Prager, W., Q., Appl. Math. 10, 157-165 (1952).

[6] Raghava, R. S., Cadell, R. and Yeh, G. S. Y., J. Mater. Sci. 8, 225-232 (1973).

[7] Dolev, G. and Ishai, O., J. Adhesion 12, 283-294 (1981).

[8] Jeandrau, J. P., Int .J. Adhesion Adhesives 11, 71-79 (1991).

[9] Lilleheden, L., Int. J. Adhesion Adhesives 14, 31-37 (1994).

[10] da Silva, L. F. M. and Adams, R. D., J. Adhesion Sci. Technol. 19, 109-141 (2005).

[11] Cognard, J. Y., Davies, P., Sohier, L. and Créac'hcadec, R., Composite Structures 76, 34-46 (2006)

[12] Créac'hcadec, R. and Cognard, J. Y., J. Adhesion 85, 239-260 (2009).

[13] Cognard, J. Y., Créac'hcadec, R., Maurice, J., Davies, P., Peleau, M. and da Silva, L. F. M., J. Adhesion Sci. Technol. 24, 1977-1994 (2010).

[14] Davies, P., Cartié, D., Peleau, M. and Partridge, I. K., Proceedings ISOPE (International Symposium on Offshore and Polar Engineering), Toulon, France (2004).

[15] Cartié, D., Davies, P., Peleau M. and Partridge, I. K., Composites: Part B 37, 292-300 (2006).

[16] Cognard, J. Y. and Creac'hcadec, R., J. Adhesion Sci. Technol. 23, 1333-1355 (2009).

[17] Cognard, J. Y., Créac’hcadec, R., Sohier, L. and Davies, P., Int. J. Adhesion Adhesives 28, 393404 (2008).

[18] Dean, G., Crocker, L., Read, B. and Wright, L., Int. J. Adhesion Adhesives 24, 295-306 (2004).

[19] Cognard, J. Y., Computers \& Structures 86, 1704-1717 (2008). 